\title{
ARTICLE \\ Kappa-opioid receptors, dynorphin, and cocaine addiction: a positron emission tomography study
}

Diana Martinez ${ }^{1}$, Mark Slifstein ${ }^{1}$, David Matuskey ${ }^{2}$, Nabeel Nabulsi ${ }^{2}$, Ming-Qiang Zheng ${ }^{2}$, Shu-fei Lin ${ }^{2}$, Jim Ropchan ${ }^{2}$, Nina Urban ${ }^{1}$, Alexander Grassetti ${ }^{1}$, Dinnisa Chang ${ }^{1}$, Michael Salling ${ }^{1}$, Richard Foltin ${ }^{1}$, Richard E. Carson ${ }^{2}$ and Yiyun Huang ${ }^{2}$

Animal studies indicate that the kappa-opioid receptor/dynorphin system plays an important role in cocaine binges and stressinduced relapse. Our goal was to investigate changes in kappa-opioid receptor (KOR) availability in the human brain using positron emission tomography (PET), before and after a cocaine binge. We also investigated the correlation between KOR and stress-induced cocaine self-administration. PET imaging was performed with the KOR selective agonist $\left[{ }^{11} \mathrm{C}\right] \mathrm{GR} 103545$. Subjects with cocaine-use disorder (CUD) underwent PET scans and performed two types of cocaine self-administration sessions in the laboratory as follows: (1) choice sessions following a cold pressor test, to induce stress, and (2) binge dosing of cocaine. This allowed us investigate the following: (1) the association between KOR binding and a laboratory model of stress-induced relapse and (2) the change in KOR binding following a 3-day cocaine binge, which is thought to represent a change in endogenous dynorphin. A group of matched healthy controls was included to investigate between group differences in KOR availability. A significant association between $\left[{ }^{11} \mathrm{C}\right]$ GR103545 binding and cocaine self-administration was seen: greater KOR availability was associated with more choices for cocaine. In addition, the 3-day cocaine binge significantly reduced $\left[{ }^{11} \mathrm{C}\right] \mathrm{GR} 103545$ binding by $18 \%$ in the striatum and $14 \%$ across brain regions. No difference in $\left[{ }^{11} \mathrm{C}\right] \mathrm{GR} 103545$ binding was found between the CUD subjects and matched controls. In the context of previous studies, these findings add to the growing evidence that pharmacotherapies targeting the KOR have the potential to significantly impact treatment development for cocaine-use disorder.

Neuropsychopharmacology (2019) 44:1720-1727; https://doi.org/10.1038/s41386-019-0398-4

\section{INTRODUCTION}

Addiction is largely driven by disturbances in reward processing and previous imaging studies have consistently shown that dopamine signaling and positive reinforcement are impaired [1, 2]. However, negative reinforcement, stress, and dysphoria also play an important role in assessing the value of a reward and signaling at the kappa-opioid receptors (KORs) can modulate these aspects of drug use [1]. To an extent, KOR and dynorphin, its endogenous ligand, have been characterized as an "anti-reward" system, and previous rodent work has shown that cocaine exposure upregulates this neurotransmitter system and increases sensitivity to stress-induced relapse [3].

At least a dozen rodent studies show that binging on cocaine greatly increases endogenous dynorphin levels in the brain. Studies measuring peptide levels showed that binge cocaine dosing increased striatal dynorphin levels by $40-100 \%[4,5]$. Subsequent studies have measured prodynorphin and preprodynorphin mRNA, and showed similar results: binge cocaine dosing increased these measures of endogenous dynorphin by a similar order of magnitude [6-15]. In humans, post-mortem studies have shown that both the KOR and dynorphin are higher in the striatum, amygdala, and prefrontal cortex in the autopsied brains of cocaine-addicted subjects [16-18].

Animal models of cocaine-use disorder (CUD) also demonstrate that the KOR/dynorphin system modulates stress-induced cocaine-seeking behavior. Dynorphin is increased in response to stress and increases the rewarding effects of cocaine (for review, see refs. [19-21]). The administration of KOR agonists is as effective as stress in animal models of relapse, whereas blockade or genetic deletion of the KOR attenuates the effects of stress on cocaine-seeking behavior (for review, see refs. [19-21]). Based on these findings, the KOR/dynorphin system has been characterized as mediating the "dark side" of addiction, where negative reinforcement spurs relapse and drug-seeking behavior [1, 22].

In this context, our goal was to investigate changes in the KOR/ dynorphin system in cocaine addiction, before and after a cocaine binge, and to correlate this with drug-seeking behavior. We developed a study based on the previous animal research, as there is often a lack of translational studies bridging the gap between rodents and clinical research. There is extensive animal data indicating that KOR antagonism could serve as a novel therapeutic approach for addiction, and there are KOR antagonists, such as LY2456302, which have been developed for human use. However, this medication has not progressed to the clinic, partly due to the need for human studies further supporting their importance. Our goal was to contribute to the body of literature supporting KOR antagonist pharmacotherapy for addiction, in the hope that this might further the development of these medications for substance-use disorders.

${ }^{1}$ Department of Psychiatry, Columbia University Irving Medical Center and the New York State Psychiatric Institute, New York, NY, USA and ${ }^{2}$ Yale PET Center, Department of Radiology and Biomedical Imaging, Yale University School of Medicine, New Haven, CT, USA

Correspondence: Diana Martinez (dm437@cumc.columbia.edu)

Received: 21 September 2018 Revised: 28 March 2019 Accepted: 16 April 2019

Published online: 26 April 2019 
Subjects with a CUD were scanned with positron emission tomography (PET) and the kappa agonist radiotracer $\left[{ }^{11} \mathrm{C}\right] \mathrm{GR} 103545$ [23-25]. The scan data were correlated with the choice to selfadminister cocaine in the laboratory (following the cold pressor test), to emulate studies in rodents investigating the association between KOR and stress-induced reinstatement. The cold pressor test was used based on previous studies showing that this induces stress in CUD participants $[26,27]$. Following this, the CUD subjects underwent binge cocaine sessions, also in the laboratory, in which they could consume up to $600 \mathrm{mg}$ smoked cocaine each day for 3 days. These sessions mimic both the rodent studies of binge cocaine exposure and the usual human pattern of binge cocaine use. Following these laboratory sessions, the CUD subjects were scanned again with $\left[{ }^{11} \mathrm{C}\right] \mathrm{GR} 103545$, where we expected decreased binding to reflect increased dynorphin levels. Lastly, a group of matched healthy control $(\mathrm{HC})$ subjects was included to compare between group differences.

\section{METHODS AND MATERIALS}

Human subjects

The cocaine subjects met Diagnostic and Statistical Manual of Mental Disorders version 5 (DSM-5) criteria for a moderate-tosevere CUD with no other current Axis I diagnosis and were actively using smoked cocaine, verified by urine toxicology. A group of matched HCs was included. Subjects were screened for medical health (physical exam, laboratory studies, and electrocardiogram) and provided informed consent. Consistent use of medications was exclusionary as was a current comorbid psychiatric diagnosis.

The CUD subjects were admitted to an in-patient research unit for all study procedures and underwent three PET scans with $\left[{ }^{11} \mathrm{C}\right]$ GR103545, under the following conditions: (1) a baseline scan, obtained after 7-8 days of abstinence (while admitted to research unit); (2) a scan following the administration of $150 \mathrm{mg}$ of naltrexone, in order to measure nonspecific binding, given the lack of a reference region for the KOR [24]; and (3) a scan following 3 days of binge cocaine self-administration, in order to measure changes in $\left[{ }^{11} \mathrm{C}\right] \mathrm{GR} 103545$ binding. The binge dosing occurred on Monday, Tuesday, and Wednesday, and the post-binge scan was obtained on Thursday. The control subjects underwent two PET scans only: before and after a dose of oral naltrexone $(150 \mathrm{mg})$. The controls participated as outpatients. The study design is illustrated in Fig. 1 and additional details are provided in the Supplementary Material.

\section{PET scans}

PET scans were performed at the Yale University Positron Emission Tomography Center. $\left[{ }^{11} \mathrm{C}\right] \mathrm{GR} 103545$ was synthesized as previously described [23]. The PET radiotracer $\left[{ }^{11} \mathrm{C}\right] \mathrm{GR} 103545$ was used given its high affinity and selectivity for the KOR, as demonstrated in previous studies $[25,28]$. The PET scans were acquired over 150 min, except the post-naltrexone scans, which were acquired over 100 min (less time needed in the blocked state). For these scans, $150 \mathrm{mg}$ of oral naltrexone was administered 60-120 min before the PET scan. Naltrexone was used to provide a measure of nonspecific binding, given that it binds to the KOR with high affinity $\left(K_{\mathrm{i}}=0.3-0.6 \mathrm{nM}\right)[29,30]$.

PET images were acquired on the high-resolution research tomograph (Siemens/CTI, Knoxville, TN) in list mode and reconstructed using the MOLAR algorithm as previously described [24]. Arterial blood was collected for the input function as described [24]. Briefly, an automated blood counting system (PBS-101, Veenstra Instruments, Joure, The Netherlands) was used for the first $7 \mathrm{~min}$ and discrete samples were obtained at 5, 15, 30,60, 90, and $120 \mathrm{~min}$ for the measurement of the percent of unmetabolized radiotracer. For the postnaltrexone scans, samples were obtained at the same time

\section{Experimental Design}

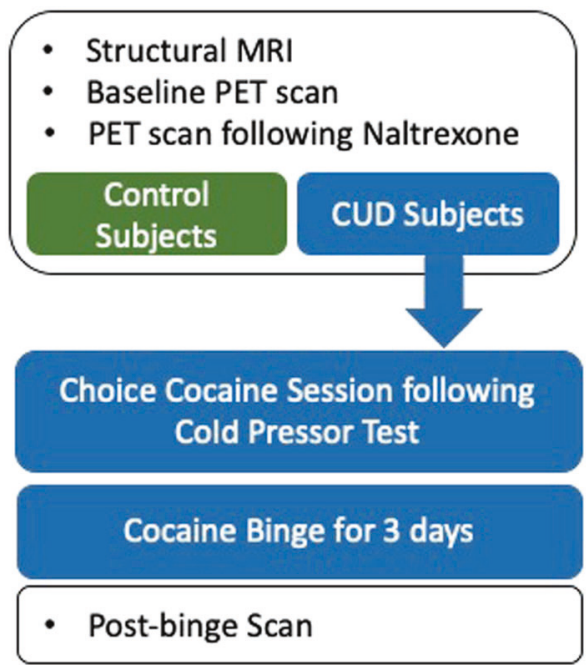

Fig. 1 Schematic illustrating experimental design. Subjects with cocaine-use disorder (CUD) were admitted to a research unit for all procedures while the healthy controls ( $\mathrm{HCs}$ ) participated as outpatients. Both the CUD participants and the HC underwent structural MRI and $\left[{ }^{11} \mathrm{C}\right] \mathrm{GR} 103545$ PET scans at baseline, and following naltrexone. The CUD subjects then performed a choice session (for money or cocaine) after a cold presssor test. Following this, the CUD subjects underwent binge cocaine sessions for 3 consecutive days followed by another scan with [ [11 C]GR103545. A representative schedule for CUD subjects is shown in the Supplementary Material

points, excluding the $120 \mathrm{~min}$ sample. The free fraction of $\left[{ }^{11} \mathrm{C}\right]$ GR103545 in plasma was determined by ultrafiltration, as described previously [24].

Each subject had a structural T1-weighted magnetic resonance imaging (MRI) scan for identification of the regions of interest (ROIs). Our primary hypothesis was limited to the striatum, based on the previous rodent and human studies. The striatum was divided into the following subdivisions: the caudate (anterior and posterior), the putamen (anterior and posterior), and the ventral striatum, which includes the nucleus accumbens, ventral caudate, and ventral putamen, as previously described (see Fig. 1 in ref. [31]. However, given the wide distribution of the KOR in the human brain, the following brain regions were included for a secondary analysis: anterior cingulate cortex, dorsolateral prefrontal cortex, medial prefrontal cortex, orbitofrontal cortex, temporal cortex, parietal cortex, occipital cortex, cerebellum, amygdala, hippocampus, and thalamus. A segmentation routine was implemented for the cortical regions so that only gray matter voxels were used to generate the time activity curves (see Fig. 2 in ref. [32]. For the bilateral brain regions, the right and left values were averaged. Co-registration between the PET and MRI scans was performed using maximization of mutual information in SPM8 software, in order to generate time activity curves, as described previously [33].

The outcome measure was the total distribution volume $\left(V_{T}\right)$, which represents the total of specific and non-displaceable binding, given the lack of a reference region for $\left[{ }^{11} \mathrm{C}\right] \mathrm{GR} 103545$ in humans [24]. $V_{\mathrm{T}}$ was obtained from the kinetic analysis using the arterial plasma activity as the input function and the MA1 method [34]. MA1 was implemented based on a previous study showing that it yielded stable estimates of $V_{T}$, in terms of bias and variance, for scan acquisitions of $120 \mathrm{~min}$ [24]. The modeling was implemented in MATLAB (MathWorks, Natick, MA) using in-house programs, as described previously [35]. 


\section{Cocaine self-administration sessions}

Two types of self-administration sessions were performed: (1) choice sessions following a cold pressor test and (2) binge cocaine sessions. The choice sessions allowed us to correlate KOR binding and cocaine-seeking behavior. The binge sessions were performed to investigate changes in $\left[{ }^{11} \mathrm{C}\right] \mathrm{GR} 103545$ binding induced by the binge dosing of cocaine. All cocaine sessions were performed with smoked cocaine as previously described [36-39].

Cocaine choice sessions

The session began with a cold pressor task (CPT), which was modified to provide the same level of exposure to cold water across subjects. Often when the CPT is performed, subjects are asked to tolerate the cold water as long as possible and to withdraw their forearm at that time. However, we wanted to avoid a situation where some subjects withdrew from the cold water after a short duration, as we had seen previously in our lab [40]. Thus, the CPT was performed with alternating warm $\left(37^{\circ} \mathrm{C}\right)$ and cold $\left(4^{\circ} \mathrm{C}\right)$ water, where subjects placed their forearm into warm water $(20 \mathrm{~s})$ followed by immersion in cold water $(20 \mathrm{~s})$, and this cycle repeated until $4 \mathrm{~min}$ had passed. Following the CPT, subjects reported anxiety and stress using a visual analog scale (57.4 \pm 17 , where the range of the scale was $0-100$ ).

After completing the CPT, subjects were asked to chose between a dose of smoked cocaine $(6 \mathrm{mg})$ and money (\$5), as performed previously by our group [38]. The choice was presented nine times, spaced 14 min apart. For each choice, there was a progressive ratio component, where the subject was required to press the space bar on the keyboard in order to receive their choice (e.g., 200, 400 presses, etc.), as described previously [38]. A progressive ratio was used to encourage subjects to weigh the two options, given that the responses required for choosing only cocaine (or only money) increases with each choice $[37,41]$. The outcome measure for these sessions was the number of times a dose of cocaine was chosen over the money (range 0-9).

Binge dose sessions

The binge self-administration sessions were performed as previously described [36, 39, 42], with some modifications. Each binge day (for a total of 3 binge days) consisted of two sessions, morning and afternoon, where six doses of $50 \mathrm{mg}$ smoked cocaine were offered to the subject, spaced $14 \mathrm{~min}$ apart. Unlike the choice sessions, the participants did not choose between cocaine and money, they were simply asked to accept or decline each dose. Thus, subjects could receive up to $600 \mathrm{mg}$ on each of 3 consecutive days, for a total of $1800 \mathrm{mg}$.

Statistical analysis

Comparison of $\mathrm{V}_{T}$ between CUD and HC. Group mean comparisons in the striatum were performed with a two group $t$-test. Comparison across all regions was performed as a linear model implemented in the mixed model framework (SPSS 24) with region as a repeated measure (compound symmetry covariance structure) and group and region as fixed effects.

The striatum was chosen a priori for statistical analysis based on the previous studies in animals and humans that reported changes in the KOR and dynorphin in this brain region [6-18]. However, given the global distribution of the KOR in the human brain, we repeated all statistical tests across cortical and subcortical regions using mixed models, in order to detect global effects.

KOR occupancy by naltrexone. Lassen plot analysis [43] was performed for each subject undergoing naltrexone administration. KOR occupancy by naltrexone and the volume of distribution in the non-displaceable compartment, $V_{\mathrm{ND}}$, were compared between groups using two group $t$-tests.
Association between $\left[{ }^{11} C\right] G R 103545 \mathrm{~V}_{T}$ and stress-induced choice to use cocaine. The Pearson's product moment was used to test for associations between baseline striatum $V_{T}$ and the number of choices. Associations across all regions were tested in the mixed model framework with region as repeated measure and the number of choices as a covariate.

Effect of binge on $\left[{ }^{11} \mathrm{C}\right] G R 103545 \mathrm{~V}_{T}$. Comparison of $V_{\mathrm{T}}$ across conditions in the striatum was performed with a paired $t$-test. Comparison across all regions was performed as a linear model implemented in the mixed model framework (SPSS 24) with region as a repeated measure and the percent change in $V_{\mathrm{T}}$ as dependent variable. Lassen plot analysis was also applied to obtain an estimate of average occupancy of KOR by dynorphin following binge.

\section{RESULTS}

Seventeen CUD subjects (all male, 14 African American, 1 Caucasian, 1 Hispanic, 1 Native American, age $43 \pm 3$ years) and 14 control subjects (all male, 10 African American, 2 Caucasian, 2 Hispanic, age $41 \pm 3$ years, $p=0.2$ for age) were included. The CUD subjects had been using cocaine for an average of $17 \pm 8$ years and were currently spending an average of $\$ 353 \pm 272$ per week on smoked cocaine. Additional demographic data are presented in the additional Supplementary Material. The PET scan parameters for each subject group and condition are shown in the additional Supplementary Material. Two group $t$-tests were performed comparing each of these parameters across groups and conditions, and all $p$-values were $>0.1$.

All of the $\mathrm{HC}$ subjects completed the baseline and naltrexone scans. However, of the 17 CUD subjects, 1 did not complete the naltrexone or the post-binge scan and another 4 did not complete the post-binge scans, and left the study early. Thus, data from 12 CUD subjects were available for the comparison of $\left[{ }^{11} \mathrm{C}\right] \mathrm{GR} 103545$ $V_{\mathrm{T}}$ before and after cocaine binge dosing.

Comparison of CUD and $\mathrm{HC}$

No significant differences were seen between the two groups for $\left[{ }^{11} \mathrm{C}\right] \mathrm{GR} 103545 V_{\mathrm{T}}$ either in striatum $(p=0.30)$ or across all brain regions (main effect of group, $\mathrm{F}(1,43.1)=0.40, p=0.531$; main effect of region, $F(16,431.7)=61.80, p<0.001$; group by region interaction, $\mathrm{F}(15,432.1)=0.680, p=0.805)$. Regional values are provided in Table 1. Two group $t$-tests on individual regions also did not reach significance for any ROI. KOR occupancy by $150 \mathrm{mg}$ PO naltrexone as estimated by Lassen plots did not differ by group (HC: $89 \pm 8 \%$, CUD: $87 \pm 15 \%, p=0.67$ ), indicating that there was no difference in nonspecific binding between the two groups (data shown in Supplementary Material). There was a trend level toward lower $V_{\mathrm{ND}}$ in CUD (HC: $2.88 \pm 0.49$, CUD: $2.35 \pm 0.97, p=$ $0.075)$, which became nonsignificant when one CUD subject with non-physiological $V_{\mathrm{ND}}(<0)$ was removed $(C U D=2.54 \pm 0.83, p=$ 0.19). On an exploratory basis, $\mathrm{BP}_{\mathrm{ND}}$ derived from $V_{\mathrm{T}}$ and the Lassen plot estimate of each subject's $V_{\mathrm{ND}}$, computed in all $\mathrm{HC}$ and the $n=15$ CUD subjects who were scanned following naltrexone, and had physiologically plausible $\mathrm{BP}_{\mathrm{ND}}$ estimates, were compared between groups. No significant differences between groups were observed in any region.

Correlation between baseline KOR binding and cocaine selfadministration

Baseline $\left[{ }^{11} \mathrm{C}\right] \mathrm{GR} 103545 V_{\mathrm{T}}$ correlated with the choice for cocaine, where higher $V_{\mathrm{T}}$ was associated with more choices for cocaine following the cold pressor test. There was a significant effect of choice in striatum $(r=0.58, p=0.014)$ as shown in Fig. 2 and across all regions (main effect of choice, $\mathrm{F}(1,17.5)=10.9, p=0.004$; choice $\times$ region interaction, $F(15,29.6)=3.7, p=0.001)$. A post-hoc analysis showed that significant effect of choice was seen in most 
Table 1. Comparison of $\left[{ }^{11} \mathrm{C}\right] \mathrm{GR} 103545 V_{\mathrm{T}}$ in the regions of interest between the healthy control and cocaine-use disorder (CUD) subjects

Comparison of $V_{\mathrm{T}}\left(\mathrm{mL} / \mathrm{cm}^{3}\right)$ across groups (HC and CUD)

\begin{tabular}{|c|c|c|c|c|c|}
\hline \multirow[t]{2}{*}{ Region of interest } & \multicolumn{2}{|c|}{$\begin{array}{l}\text { Controls } \\
(n=14)\end{array}$} & \multicolumn{2}{|c|}{$\begin{array}{l}\text { CUD } \\
\text { subjects } \\
(n=17)\end{array}$} & \multirow[b]{2}{*}{$p$} \\
\hline & Mean & SD & Mean & SD & \\
\hline Striatum & 11.34 & 3.07 & 10.31 & 2.33 & 0.30 \\
\hline Ventral striatum & 16.73 & 7.04 & 15.78 & 4.67 & 0.66 \\
\hline Anterior putamen & 13.74 & 3.88 & 12.52 & 2.61 & 0.31 \\
\hline Posterior putamen & 9.24 & 2.34 & 8.70 & 1.87 & 0.48 \\
\hline Anterior caudate & 11.21 & 3.30 & 9.87 & 2.65 & 0.22 \\
\hline Posterior caudate & 6.43 & 1.48 & 6.04 & 1.98 & 0.55 \\
\hline Anterior cingulate cortex & 17.77 & 4.70 & 17.42 & 6.32 & 0.86 \\
\hline Dorsolateral prefrontal cortex & 14.99 & 3.95 & 13.42 & 3.60 & 0.25 \\
\hline Medial prefrontal cortex & 15.65 & 4.89 & 14.90 & 4.18 & 0.65 \\
\hline Orbitofrontal cortex & 14.41 & 3.77 & 13.00 & 3.69 & 0.30 \\
\hline Temporal cortex & 14.08 & 4.25 & 12.94 & 3.69 & 0.43 \\
\hline Parietal cortex & 14.00 & 3.60 & 12.69 & 3.32 & 0.30 \\
\hline Occipital cortex & 11.79 & 3.26 & 11.01 & 2.69 & 0.47 \\
\hline Cerebellum & 7.66 & 3.54 & 8.00 & 1.79 & 0.73 \\
\hline Amygdala & 18.02 & 8.54 & 15.28 & 7.07 & 0.34 \\
\hline Hippocampus & 8.08 & 1.86 & 8.12 & 1.75 & 0.96 \\
\hline Thalamus & 5.98 & 1.31 & 5.78 & 1.04 & 0.64 \\
\hline
\end{tabular}

No significant difference in $V_{\mathrm{T}}$ was seen between the two groups in the striatum or other brain regions. The values presented are mean and SD and the $p$-values were obtained with a two-tailed unpaired $t$-test

brain regions, including the striatum, hippocampus, cingulate cortex, and other regions of the cortex, as shown in Table 2. The significant interaction term was due to differing magnitude of the linear relationship across regions, with slope near 0 in cerebellum ( $1 \%$ of mean $V_{\mathrm{T}}$ ), between 0.1 and 0.37 in most subcortical regions $\left(2-4 \%\right.$ of mean $\left.V_{T}\right)$, and between 0.58 and 1.0 in most cortical regions $\left(4-7 \%\right.$ of mean $\left.V_{\mathrm{T}}\right)$.

A post-hoc analysis was performed across regions in the mixed model framework, investigating correlations between craving for cocaine, years of cocaine use, and amount of use prior to study entry. No significant association was seen between KOR binding and subjects' ratings of "anxiety/stress" following the cold pressor test $(\mathrm{F}(1,14.99)=2.184, p=0.16)$, although there was a correlation between subjects' rating of "anxiety/stress" and the choice for cocaine $(r=0.56, p=0.02)$. There was no significant association between craving or years of use and $V_{\mathrm{T}}$. However, there was a significant association between amount of cocaine use and KOR binding $(\mathrm{F}(1,41.77)=5.33, p=0.03)$.

Effect of binge dosing of cocaine on PET radiotracer binding The CUD subjects took $1529 \pm 429 \mathrm{mg}$ of smoked cocaine. The values of $\left[{ }^{11} \mathrm{C}\right] \mathrm{GR} 103545 V_{\mathrm{T}}$ before and after the binge dosing of cocaine are shown in Table 3. $\left[{ }^{11} \mathrm{C}\right] \mathrm{GR} 103545 V_{\mathrm{T}}$ was significantly reduced by $18 \%$ in the striatum and by $14 \%$ across brain regions when comparing the post-binge scan to the pre-binge scan (shown in Fig. 2). There was no main effect of ROl; percent change did not vary significantly across ROls (percent change in $V_{T}, F(1,10.99)=$ 4.832, $p=0.05$; main effect of region, $\mathrm{F}(15,162.0)=1.11, p=0.355)$. Figure 2 also shows the change in $V_{T}$ for the striatum only (for clarity, not all brain regions included) and this shows that $V_{\mathrm{T}}$ was reduced after binge dosing of cocaine. Average occupancy of KOR following binge, estimated by Lassen plot analysis, was $23 \pm 26 \%$.
The time between the last binge dose and the post-binge scan was $19.2 \pm 2.4 \mathrm{~h}$. A post-hoc analysis showed no correlation between the timing of the post-binge PET scan and the decrease in $\left[{ }^{11} \mathrm{C}\right]$ GR103545 $V_{\mathrm{T}}$. There was no association between the choice for cocaine (following the cold pressor test) and the change in $\left[{ }^{11} \mathrm{C}\right]$ GR103545 $V_{\mathrm{T}}$ following the binge of cocaine. Correlations did not reach significance in any individual regions either.

\section{DISCUSSION}

The main findings of this study are as follows: (1) no difference in $\left[{ }^{11} \mathrm{C}\right] \mathrm{GR} 103545$ binding was seen between CUD and the healthy comparison subjects; (2) baseline $\left[{ }^{11} \mathrm{C}\right] \mathrm{GR} 103545 V_{\mathrm{T}}$ correlated with cold pressor-induced cocaine self-administration, where higher $V_{\mathrm{T}}$ predicted more choices for cocaine; and (3) binge dosing of cocaine resulted in a decrease of $\left[{ }^{11} \mathrm{C}\right] \mathrm{GR} 103545 V_{T}$, which may represent an increase in endogenous dynorphin. The relevance of each of these findings to the existing literature is discussed below.

\section{Comparison of KOR in CUD subjects and controls}

Three previous human post-mortem studies have shown that cocaine dependence is associated with an upregulation of the KOR compared with controls. However, we found no significant difference in $\left[{ }^{11} \mathrm{C}\right] \mathrm{GR} 103545 V_{\mathrm{T}}$ in this study. The group mean $V_{\mathrm{T}}$ values were slightly lower in CUD across most regions, although this might be partially accounted for by slightly lower $V_{N D}$, as observed in the post-naltrexone Lassen plots. When Lassen plotderived binding potentials were compared between $\mathrm{HC}$ subjects and the CUD, mean $\mathrm{BP}_{\mathrm{ND}}$ in all brain regions was slightly but not significantly higher in CUD (e.g., in the striatum, $\mathrm{BP}_{\mathrm{ND}}=3.35 \pm 0.99$ in CUD, $\mathrm{BP}_{\mathrm{ND}}=2.98 \pm 1.06$ in $\mathrm{HC}, p=0.34$ ). We also found no difference in $V_{\mathrm{T}}$ between the groups, indicating that there was no difference in nonspecific binding.

In the post-mortem studies, Hurd and Herkenham [16] reported an increase in the caudate, with no group differences in the putamen and nucleus accumbens. Subsequently, Mash et al. [17] reported that the KOR was increased in the nucleus accumbens, anterior and ventral caudate and putamen, and the basolateral amygdala. Staley et al. [18] measured KOR binding in cocaine overdose victims and controls, and reported an increase in the nucleus accumbens, medial caudate and putamen, amygdala, cingulate cortex, and orbitofrontal cortex. Increases were not found in other brain regions, such as the dorsolateral striatum or cortical regions (temporal lobe, insula, and premotor cortex) [18].

It is possible that we did not replicate the post-mortem findings with the present PET study due to differences in subject selection. In the post-mortem studies, the cocaine-dependent subjects died with high levels of cocaine on board and often from cocaine toxicity. This is not the case in the PET study, where subjects were using high, but not toxic, doses of cocaine and were abstinent from cocaine for at least 7 days before baseline scanning.

An additional reason could be differences in endogenous dynorphin between the two groups, as PET measures only the available receptors. In other words, if the CUD subjects had higher levels of dynorphin compared with the control subjects, this could result in no detectable difference in $V_{T}$ between the two groups, i.e., higher $B_{\max }$ in CUD but similar $B_{\text {avail }}$ across groups due to masking of KOR availability by baseline dynorphin binding. We scanned the CUD subjects after 7-8 days of monitored in-patient abstinence, in order to avoid scanning when endogenous levels of dynorphin may be elevated, due to cocaine use before study admission. However, this time frame is based on rodent studies and it is possible that the human CUD subjects still had higher levels of endogenous dynorphin compared with controls, masking KOR availability. Future studies imaging the KOR at other time points of abstinence would be required to address this possibility. 


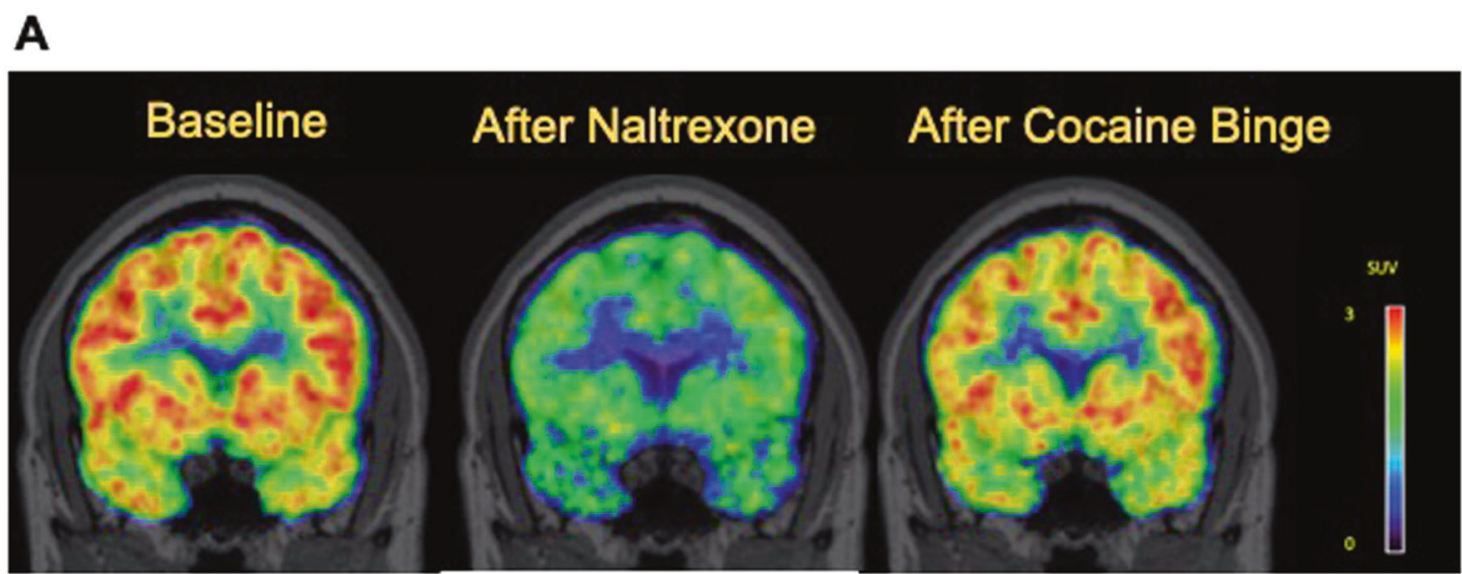

B

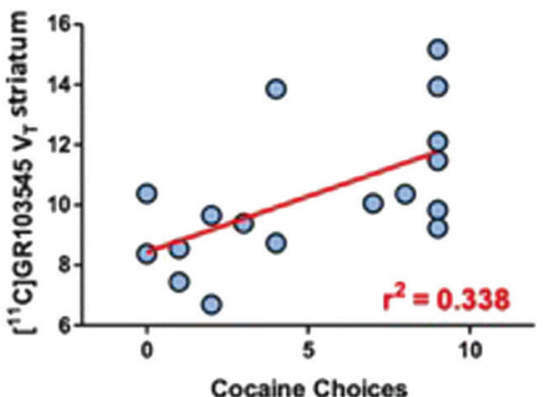

C

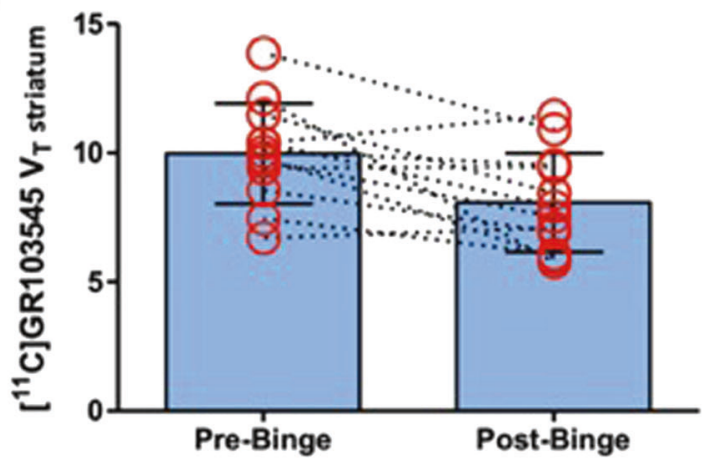

Fig. 2 PET scan results. a Representative PET images taken from CUD subject at baseline, after naltrexone, and after a cocaine binge demonstrating a reduction in $\left[{ }^{11} \mathrm{C}\right] \mathrm{GR} 103545$ standard uptake value (SUV). b Number of cocaine choices of CUD subjects during cocaine choice session (maximum $=9$ ) and its relationship with binding of $\left[{ }^{11} \mathrm{C}\right] \mathrm{GR} 103545 V_{\mathrm{T}}$ in the striatum. $\mathrm{c}$ Values for $\left[{ }^{11} \mathrm{C}\right] \mathrm{GR} 103545 V_{\mathrm{T}}$ before and after the cocaine binge in the striatum for each subject. Similar decreases were observed across all ROls

\begin{tabular}{|lcc|}
\hline $\begin{array}{l}\text { Table 2. The Pearson's product moment }(r) \text { and significance levels for } \\
\text { association between baseline } V_{\mathrm{T}} \text { and the number of times subjects } \\
\text { chose cocaine }\end{array}$ & $r$ & \\
\hline Region of interest & 0.58 & 0.01 \\
\hline Striatum & 0.64 & $<0.01$ \\
Ventral striatum & 0.52 & 0.032 \\
Anterior caudate & 0.53 & 0.03 \\
Posterior caudate & 0.49 & 0.05 \\
Anterior putamen & 0.68 & $<0.01$ \\
Posterior putamen & 0.58 & 0.01 \\
Anterior cingulate cortex & 0.71 & $<0.01$ \\
Dorsolateral prefrontal cortex & 0.78 & $<0.01$ \\
Medial prefrontal cortex & 0.70 & $<0.01$ \\
Orbitofrontal cortex & 0.58 & 0.01 \\
Temporal cortex & 0.64 & $<0.01$ \\
Parietal cortex & 0.52 & 0.03 \\
Occipital cortex & 0.08 & 0.80 \\
Cerebellum & 0.47 & 0.06 \\
Amygdala & 0.52 & 0.03 \\
Hippocampus & 0.58 & 0.02 \\
Thalamus & & \\
& &
\end{tabular}

Correlation between KOR and cocaine self-administration

We found that baseline KOR binding correlated with the choice to self-administer cocaine following the cold pressor test, used to provoke stress-induced cocaine-seeking behavior in the laboratory. The results suggest that higher levels of KOR in the striatum and most other brain regions, may be associated with a greater vulnerability to stress-induced relapse in CUDs.

Although PET can demonstrate differences in receptor binding, it cannot be used to confirm that greater receptor availability translates into increased signaling. Thus, this finding alone cannot confirm that increased KOR signaling is associated with drugseeking behavior. However, taken in the context of animal studies, this finding adds to the evidence showing that blocking the KOR may be beneficial. In animal studies, both physical and social stressors increase cocaine-seeking behavior and this effect is blocked by the administration of KOR antagonists (for review, see ref. [2]). Repeated stress in rats shifts the behavioral economics of cocaine, increasing its value and the maximum price that they are willing to pay for cocaine, and KOR antagonists can prevent or even reverse this effect $[44,45]$. In our study, CUD subjects were asked to choose between alternative reinforcers, cocaine, and money. Subjects with higher levels of KOR availability chose cocaine over money, following a stressor, indicating that KOR binding plays a role in the economics of cocaine use, and that blocking the receptor may enhance resilience to stress-induced relapse. 
Table 3. Comparison of $\left[{ }^{11} \mathrm{C}\right] \mathrm{GR} 103545 V_{\mathrm{T}}$ in the regions of interest in the CUD group before and after binge dosing of cocaine

\begin{tabular}{|c|c|c|c|c|c|c|}
\hline \multicolumn{7}{|c|}{ Comparison of pre- and post-binge $V_{\mathrm{T}}\left(\mathrm{mL} / \mathrm{cm}^{3}\right)$} \\
\hline \multirow[t]{2}{*}{ Region of interest } & \multicolumn{2}{|c|}{ Pre-binge } & \multicolumn{2}{|c|}{ Post-binge } & \multirow{2}{*}{$\begin{array}{l}\text { Percent change } \\
\%\end{array}$} & \multirow[t]{2}{*}{$p$} \\
\hline & Mean & SD & Mean & SD & & \\
\hline Striatum & 9.98 & 1.95 & 8.08 & 1.91 & $-17.7 \pm 18.3$ & 0.01 \\
\hline Ventral striatum & 14.40 & 3.66 & 11.04 & 3.09 & $-16.5 \pm 26.7$ & 0.05 \\
\hline Anterior caudate & 9.61 & 2.33 & 7.90 & 1.97 & $-16.3 \pm 18.0$ & 0.02 \\
\hline Posterior caudate & 5.78 & 2.13 & 4.38 & 1.09 & $-19.9 \pm 21.0$ & 0.03 \\
\hline Anterior putamen & 12.22 & 2.15 & 10.06 & 2.86 & $-17.0 \pm 19.5$ & 0.01 \\
\hline Posterior putamen & 8.48 & 1.71 & 6.72 & 1.73 & $-19.1 \pm 20.0$ & 0.01 \\
\hline $\begin{array}{l}\text { Anterior } \\
\text { cingulate cortex }\end{array}$ & 15.25 & 3.53 & 13.01 & 3.01 & $-10.8 \pm 25.2$ & 0.10 \\
\hline $\begin{array}{l}\text { Dorsolateral } \\
\text { prefrontal cortex }\end{array}$ & 12.69 & 2.64 & 11.04 & 2.86 & $-10.4 \pm 23.4$ & 0.12 \\
\hline $\begin{array}{l}\text { Medial } \\
\text { prefrontal cortex }\end{array}$ & 13.93 & 3.12 & 11.18 & 2.87 & $-16.7 \pm 2$ & 0.03 \\
\hline Orbitofrontal cortex & 12.47 & 2.80 & 11.35 & 3.74 & $-5.4 \pm 33.6$ & 0.20 \\
\hline Temporal cortex & 12.11 & 2.04 & 10.26 & 2.45 & $-13.5 \pm 22.2$ & 0.05 \\
\hline Parietal cortex & 11.97 & 2.30 & 9.93 & 2.44 & $-14.7 \pm 22.7$ & 0.05 \\
\hline Occipital cortex & 10.50 & 1.95 & 8.57 & 2.11 & $-16.9 \pm 20.0$ & 0.02 \\
\hline Cerebellum & 7.80 & 1.58 & 6.36 & 2.08 & $-16.9 \pm 20.1$ & 0.02 \\
\hline Amygdala & 12.38 & 2.28 & 9.98 & 2.40 & $-9.1 \pm 38.1$ & 0.30 \\
\hline Hippocampus & 7.70 & 1.44 & 6.31 & 1.57 & $-15.2 \pm 18.0$ & 0.04 \\
\hline Thalamus & 5.60 & 0.88 & 4.61 & 0.97 & $-16.3 \pm 20.0$ & 0.01 \\
\hline
\end{tabular}

$V_{\mathrm{T}}$ was significantly reduced across brain regions using a linear model implemented in the mixed model framework, with no main effect of ROI. A post-hoc paired $t$-test was performed on the ROI and reported below

A post-hoc analysis showed that $\left[{ }^{11} \mathrm{C}\right] \mathrm{GR} 103545 V_{\mathrm{T}}$ correlated with the amount of cocaine use before study entry, assessed by the subjects' self-report of the dollar amount spent on cocaine in the month before hospitalization. Thus, greater cocaine use before study entry was associated with higher levels of KOR. This suggests that greater cocaine use may impact KOR availability, and that this effect persists despite the 7-8 days of abstinence before the baseline PET scan.

Effect of binge cocaine dosing on PET measures of KOR In CUD subjects, binge dosing of cocaine reduced [ $\left.{ }^{11} \mathrm{C}\right] \mathrm{GR} 103545$ binding to the KOR. We used a 3-day binge of cocaine in the laboratory, in order to model the previous studies in rodents and binge cocaine use in humans. The post-binge scan with $\left[{ }^{11} \mathrm{C}\right]$ GR103545 showed a decrease in $\left[{ }^{11} \mathrm{C}\right] \mathrm{GR} 103545 V_{\mathrm{T}}$ of $14.4 \%$ across all brain regions.

We interpret this decrease as representing an increase in endogenous dynorphin, which would reduce KOR availability for tracer binding. At least a dozen rodent studies have shown that binge cocaine increases endogenous dynorphin, prodynorphin mRNA, and preprodynorphin mRNA [4-15]. The increase in dynorphin could be detected as early as $1 \mathrm{~h}$ and remained elevated at $48 \mathrm{~h}$ after binge administration of cocaine.

Similar results have been shown in monkeys and humans. Fagergren et al. [46] showed that rhesus monkeys who selfadministered cocaine for five sessions had an increase in prodynorphin mRNA levels in the caudate and putamen at $1 \mathrm{~h}$ after the last dose. In humans, Hurd and Herkenham [16] reported that CUD was associated with an increase in preprodynorphin mRNA in the putamen and caudate in a post-mortem study. More recently, Frankel et al. [47] measured dynorphin peptide levels in both striatal and extra-striatal brain regions in a post-mortem study of cocaine abusers and controls. The results showed a significant increase in the caudate (92\%) and an increase in the putamen $(75 \%)$ that trended toward significance.

Our results extend these findings by showing that $\left[{ }^{11} \mathrm{C}\right]$ GR103545 binding is reduced by binge dosing of cocaine in humans in vivo. We interpret this decrease as representing an increase in endogenous dynorphin levels. Although the exact mechanism of this is unclear, recent PET imaging studies in rodents show that $\left[{ }^{11} \mathrm{C}\right] \mathrm{GR} 103545$ binding is reduced by the administration of KOR agonists (salvinorin and U-50488), whereas kappa receptor antagonist radiotracers were not affected [48, 49]. Previous PET studies have imaged changes in endogenous neurotransmitters, such as dopamine or endorphin, using a dopamine $\mathrm{D}_{2}$ or $\mathrm{mu}$ receptor radiotracers, indicating that a change in radiotracer binding can be used to indirectly measure increases in neurotransmitter levels $[50,51]$. In this study, the mechanism behind the decrease in $\left[{ }^{11} \mathrm{C}\right] \mathrm{GR} 103545 V_{T}$ has not been identified. It may involve competition for the KOR between the radiotracer and endogenous dynorphin, internalization or downregulation of the KOR, or a combination of these mechanisms. Future animal studies would be required to address each of these questions.

\section{Limitations}

There are some limitations to this study. The first is that it includes a relatively small number of subjects, who are all male. This prevents us from investigating sex differences in KOR binding. An additional limitation is that the control subjects were scanned at baseline and after naltrexone, but not at an additional time point that would have mirrored the post-binge scan in the CUD subjects. Thus, we cannot rule out the possibility that the post-binge scan in the CUD was not affected by the naltrexone scan. As the CUD subjects were admitted to an in-patient research unit for this study, which lacks the stressors and cues of the real-world setting, we cannot assess the impact of this in the present study. We also cannot rule out that changes living conditions, hydration, or food intake did not contribute to alterations in KOR availability. Thus, ideally, a CUD group that did not undergo cocaine sessions would have improved our interpretation of these findings.

We did not see an association between the subjects' self-report of "anxiety/stress" (visual analog scale) and $V_{\mathrm{T}}$, although there was a correlation between the VAS measure and cocaine selfadministration. In addition, four of CUD subjects left the study before the binge portion of the study, mostly due to the extensive study procedures (including arterial line placement and a long scan time). Thus, it is possible that these subjects may have had a different response to the cocaine binge.

\section{CONCLUSION}

In summary, the results from this study are in agreement with previous studies indicating that KOR antagonism would serve as an innovative treatment for addiction. Rodent studies have consistently shown that KOR antagonists do not affect the "euphoric-like" effects of drugs but instead block the stressinduced potentiation of drug reward and the escalation of drug consumption [22, 52]. However, despite the fact the research indicates that KOR antagonism could disrupt the addiction cycle, these medications are not available to treat addiction. Progress had been made with the KOR antagonist LY2456302, which was developed by Eli Lilly and Company, and found to have a good safety profile in humans. The compound has since been licensed to Cerecor and now Janssen Pharmaceuticals, and may become available for clinical studies.

In addition to CUD, there is data supporting a role for KOR antagonism in alcohol, tobacco, and methamphetamine addiction 
$[22,53-55]$. Our hope is that this study might contribute to the scientific data supporting a role for KOR antagonists as a novel treatment approach for a refractory disorder that affects almost 40 million Americans.

\section{FUNDING AND DISCLOSURE}

This research was supported by the National Institute on Drug Abuse (NIDA) grant 1R01DA027777-01. This publication was made possible by CTSA Grant Number UL1 TR000142 from the National Center for Advancing Translational Science (NCATS), a component of the National Institutes of Health $(\mathrm{NIH})$. Its contents are solely the responsibility of the authors and do not necessarily represent the official view of $\mathrm{NIH}$. The authors declare no competing interest.

\section{ACKNOWLEDGEMENTS}

We thank Margaret Haney PhD for her input on binge cocaine dosing and Charles Chavkin PhD for his input on study design regarding previous rodent work.

\section{ADDITIONAL INFORMATION}

Supplementary Information accompanies this paper at (https://doi.org/10.1038/ s41386-019-0398-4).

Publisher's note: Springer Nature remains neutral with regard to jurisdictional claims in published maps and institutional affiliations.

\section{REFERENCES}

1. Koob GF. Neurobiological substrates for the dark side of compulsivity in addiction. Neuropharmacology. 2009;56:18-31.

2. Trifilieff $P$, Martinez $D$. Kappa-opioid receptor signaling in the striatum as a potential modulator of dopamine transmission in cocaine dependence. Front Psychiatry. 2013;4:44.

3. Shippenberg TS, Herz A. Differential effects of mu and kappa opioid systems on motivational processes. NIDA Res Monogr. 1986;75:563-6.

4. Sivam SP. Cocaine selectively increases striatonigral dynorphin levels by a dopaminergic mechanism. J Pharmacol Exp Ther. 1989;250:818-24.

5. Smiley $\mathrm{PL}$, Johnson M, Bush L, Gibb JW, Hanson GR. Effects of cocaine on extrapyramidal and limbic dynorphin systems. J Pharmacol Exp Ther. 1990; 253:938-43.

6. Daunais JB, Roberts DC, McGinty JF. Cocaine self-administration increases preprodynorphin, but not c-fos, mRNA in rat striatum. Neuroreport. 1993;4:543-6.

7. Daunais JB, Roberts DC, McGinty JF. Short-term cocaine self administration alters striatal gene expression. Brain Res Bull. 1995b;37:523-7.

8. Jenab S, Festa ED, Russo SJ, Wu HB, Inturrisi CE, Quinones-Jenab V. MK-801 attenuates cocaine induction of c-fos and preprodynorphin mRNA levels in Fischer rats. Brain Res Mol Brain Res. 2003;117:237-9.

9. Schlussman SD, Zhang Y, Yuferov V, LaForge KS, Ho A, Kreek MJ. Acute 'binge' cocaine administration elevates dynorphin mRNA in the caudate putamen of C57BL/6J but not 129/J mice. Brain Res. 2003;974:249-53.

10. Schlussman SD, Zhou Y, Bailey A, Ho A, Kreek MJ. Steady-dose and escalatingdose "binge" administration of cocaine alter expression of behavioral stereotypy and striatal preprodynorphin mRNA levels in rats. Brain Res Bull. 2005;67:169-75.

11. Spangler R, Ho A, Zhou Y, Maggos CE, Yuferov V, Kreek MJ. Regulation of kappa opioid receptor mRNA in the rat brain by "binge' pattern cocaine administration and correlation with preprodynorphin mRNA. Brain Res Mol Brain Res. 1996;38:71-6.

12. Spangler R, Unterwald E, Kreek M. Binge cocaine administration induces a sustained increase of prodynorphin mRNA in rat caudate-putamen. Brain Res Mol Brain Res. 1993;19:323-7.

13. Zhou Y, Spangler R, Schlussman SD, Yuferov VP, Sora I, Ho A, et al. Effects of acute "binge" cocaine on preprodynorphin, preproenkephalin, proopiomelanocortin, and corticotropin-releasing hormone receptor mRNA levels in the striatum and hypothalamic-pituitary-adrenal axis of mu-opioid receptor knockout mice. Synapse. 2002;45:220-9.

14. Daunais JB, McGinty JF. Cocaine binges differentially alter striatal preprodynorphin and zif/268 mRNAs. Brain Res Mol Brain Res. 1995a;29:201-10.

15. Daunais JB, McGinty JF. The effects of D1 or D2 dopamine receptor blockade on zif/268 and preprodynorphin gene expression in rat forebrain following a shortterm cocaine binge. Brain Res Mol Brain Res. 1996;35:237-48.
16. Hurd $\mathrm{YL}$, Herkenham M. Molecular alterations in the neostriatum of human cocaine addicts. Synapse. 1993;13:357-69.

17. Mash DC, Staley JK. D3 dopamine and kappa opioid receptor alterations in human brain of cocaine-overdose victims. Ann N Y Acad Sci. 1999;877:507-22.

18. Staley JK, Rothman RB, Rice KC, Partilla J, Mash DC. Kappa2 opioid receptors in limbic areas of the human brain are upregulated by cocaine in fatal overdose victims. J Neurosci. 1997;17:8225-33.

19. Muschamp JW, Carlezon WA Jr. Roles of nucleus accumbens CREB and dynorphin in dysregulation of motivation. Cold Spring Harb Perspect Med. 2013;3:a012005.

20. Bruchas MR, Land BB, Chavkin C. The dynorphin/kappa opioid system as a modulator of stress-induced and pro-addictive behaviors. Brain Res. 2010; 1314:44-55

21. Wee S, Koob GF. The role of the dynorphin-kappa opioid system in the reinforcing effects of drugs of abuse. Psychopharmacology. 2010;210:121-35.

22. Chavkin C, Koob GF. Dynorphin, dysphoria, and dependence: the stress of addiction. Neuropsychopharmacology. 2016;41:373-4.

23. Nabulsi NB, Zheng MQ, Ropchan J, Labaree D, Ding YS, Blumberg L, et al. [11C] GR103545: novel one-pot radiosynthesis with high specific activity. Nucl Med Biol. 2011;38:215-21.

24. Naganawa M, Jacobsen LK, Zheng MQ, Lin SF, Banerjee A, Byon W, et al. Evaluation of the agonist PET radioligand [(1)(1)C]GR103545 to image kappa opioid receptor in humans: kinetic model selection, test-retest reproducibility and receptor occupancy by the antagonist PF-04455242. Neurolmage. 2014;99:69-79.

25. Schoultz BW, Hjornevik T, Willoch F, Marton J, Noda A, Murakami Y, et al. Evaluation of the kappa-opioid receptor-selective tracer [(11)C]GR103545 in awake rhesus macaques. Eur J Nucl Med Mol Imaging. 2010;37:1174-80.

26. Back SE, Brady KT, Jackson JL, Salstrom S, Zinzow H. Gender differences in stress reactivity among cocaine-dependent individuals. Psychopharmacology. 2005;180:169-76.

27. Compton MA. Cold-pressor pain tolerance in opiate and cocaine abusers: correlates of drug type and use status. J Pain Symptom Manag. 1994;9:462-73.

28. Talbot PS, Narendran R, Butelman ER, Huang Y, Ngo K, Slifstein M, et al. 11CGR103545, a radiotracer for imaging kappa-opioid receptors in vivo with PET: synthesis and evaluation in baboons. J Nucl Med. 2005;46:484-94.

29. Peng XM, Knapp BI, Bidlack JM, Neumeyer JL. Pharmacological properties of bivalent ligands containing butorphan linked to nalbuphine, naltrexone, and naloxone at mu, delta, and kappa opioid receptors. J Med Chem. 2007;50:2254-8.

30. Butelman ER, Rus S, Prisinzano TE, Kreek MJ. The discriminative effects of the kappa-opioid hallucinogen salvinorin $A$ in nonhuman primates: dissociation from classic hallucinogen effects. Psychopharmacology. 2010;210:253-62.

31. Martinez D, Slifstein M, Broft A, Mawlawi O, Hwang DR, Huang Y, et al. Imaging human mesolimbic dopamine transmission with positron emission tomography. Part II: amphetamine-induced dopamine release in the functional subdivisions of the striatum. J Cereb Blood Flow Metab. 2003;23:285-300.

32. Abi-Dargham A, Martinez D, Mawlawi O, Simpson N, Hwang DR, Slifstein M, et al. Measurement of striatal and extrastriatal dopamine D1 receptor binding potential with [11C]NNC 112 in humans: validation and reproducibility. J Cereb Blood Flow Metab. 2000;20:225-43.

33. Girgis RR, Xu X, Gil RB, Hackett E, Ojeil N, Lieberman JA, et al. Antipsychotic binding to the dopamine-3 receptor in humans: a PET study with [(11)C](+)-PHNO. Schizophr Res. 2015;168:373-6.

34. Ichise M, Toyama H, Innis RB, Carson RE. Strategies to improve neuroreceptor parameter estimation by linear regression analysis. J Cereb Blood Flow Metab. 2002;22:1271-81.

35. Slifstein M, van de Giessen E, Van Snellenberg J, Thompson JL, Narendran R, Gil R, et al. Deficits in prefrontal cortical and extrastriatal dopamine release in schizophrenia: a positron emission tomographic functional magnetic resonance imaging study. JAMA Psychiatry. 2015;72:316-24.

36. Foltin RW, Fischman MW. Residual effects of repeated cocaine smoking in humans. Drug Alcohol Depend. 1997;47:117-24.

37. Haney M, Rubin E, Foltin RW. Aripiprazole maintenance increases smoked cocaine self-administration in humans. Psychopharmacology. 2011;216:379-87.

38. Martinez D, Slifstein M, Narendran R, Foltin RW, Broft A, Hwang DR, et al. Dopamine D1 receptors in cocaine dependence measured with PET and the choice to self-administer cocaine. Neuropsychopharmacology. 2009;34:1774-82.

39. Ward AS, Haney M, Fischman MW, Foltin RW. Binge cocaine self-administration by humans: smoked cocaine. Behav Pharmacol. 1997;8:736-44.

40. Kowalczyk WJ, Evans SM, Bisaga AM, Sullivan MA, Comer SD. Sex differences and hormonal influences on response to cold pressor pain in humans. J Pain. 2006;7:151-60.

41. Vadhan NP, Hart CL, Haney M, van Gorp WG, Foltin RW. Decision-making in longterm cocaine users: effects of a cash monetary contingency on Gambling task performance. Drug Alcohol Depend. 2009;102:95-101.

42. Foltin RW, Ward AS, Collins ED, Haney M, Hart CL, Fischman MW. The effects of venlafaxine on the subjective, reinforcing, and cardiovascular effects of cocaine 
in opioid-dependent and non-opioid-dependent humans. Exp Clin Psychopharmacol. 2003;11:123-30.

43. Cunningham VJ, Rabiner EA, Slifstein M, Laruelle M, Gunn RN. Measuring drug occupancy in the absence of a reference region: the Lassen plot re-visited. J Cereb Blood Flow Metab. 2010;30:46-50.

44. Groblewski PA, Zietz C, Willuhn I, Phillips PE, Chavkin C. Repeated stress exposure causes strain-dependent shifts in the behavioral economics of cocaine in rats. Addict Biol. 2015;20:297-301.

45. Polter AM, Bishop RA, Briand LA, Graziane NM, Pierce RC, Kauer JA. Poststress block of kappa opioid receptors rescues long-term potentiation of inhibitory synapses and prevents reinstatement of cocaine seeking. Biol Psychiatry. 2014;76:785-93.

46. Fagergren $P$, Smith HR, Daunais JB, Nader MA, Porrino LJ, Hurd YL. Temporal upregulation of prodynorphin mRNA in the primate striatum after cocaine selfadministration. Eur J Neurosci. 2003;17:2212-8.

47. Frankel PS, Alburges ME, Bush L, Hanson GR, Kish SJ. Striatal and ventral pallidum dynorphin concentrations are markedly increased in human chronic cocaine users. Neuropharmacology. 2008;55:41-6.

48. Placzek MS, Schroeder FA, Che T, Wey HY, Neelamegam R, Wang $C$, et al Discrepancies in kappa opioid agonist binding revealed through PET imaging. ACS Chem Neurosci. 2018;10:384-95.
49. Placzek MS, Van de Bittner GC, Wey HY, Lukas SE, Hooker JM. Immediate and persistent effects of salvinorin $A$ on the kappa opioid receptor in rodents, monitored in vivo with PET. Neuropsychopharmacology. 2015;40:2865-72.

50. Laruelle M. Imaging synaptic neurotransmission with in vivo binding competition techniques: a critical review. J Cereb Blood Flow Metab. 2000;20:423-51.

51. Placzek MS, Zhao W, Wey HY, Morin TM, Hooker JM. PET neurochemical imaging modes. Semin Nucl Med. 2016;46:20-27.

52. Tejeda HA, Bonci A. Dynorphin/kappa-opioid receptor control of dopamine dynamics: Implications for negative affective states and psychiatric disorders. Brain Res. 2018;pii: S0006-8993:30488-8.

53. Tejeda HA, Natividad LA, Orfila JE, Torres OV, O'Dell LE. Dysregulation of kappa-opioid receptor systems by chronic nicotine modulate the nicotine withdrawal syndrome in an age-dependent manner. Psychopharmacology. 2012;224:289-301.

54. Walker BM, Zorrilla EP, Koob GF. Systemic kappa-opioid receptor antagonism by nor-binaltorphimine reduces dependence-induced excessive alcohol selfadministration in rats. Addict Biol. 2011;16:116-9.

55. Whitfield TW Jr., Schlosburg JE, Wee S, Gould A, George O, Grant Y, et al. kappa Opioid receptors in the nucleus accumbens shell mediate escalation of methamphetamine intake. J Neurosci. 2015;35:4296-305. 